\title{
Non-Invasive Internal Wound Healing
}

\section{Andrew Hague ${ }^{*}$}

President, Cellsonic: Manufacturers of Medical Equipment, United Kingdom

*Corresponding author: Andrew Hague, President, Cellsonic: Manufacturers of Medical Equipment, United Kingdom, Tel: +1 315 210 6307, E-mail: cellsonic.beauty@gmail.com

Received: January 25, 2016 Accepted: January 29, 2016 Published: Feb 02, 2016

Copyright: (c) 2016 Hague A. This is an open-access article distributed under the terms of the Creative Commons Attribution License, which permits unrestricted use, distribution, and reproduction in any medium, provided the original author and source are credited.

\section{Non-Invasive Internal Wound Healing}

Forty years ago CellSonic's technology started by removing kidney stones with sound non-invasively and went on to become the best way to heal bones, wounds and nerves by removing infection and causing migration of stem cells. From expertise in healing external wounds, we now go back to where we started healing internal wounds. This means that invasive surgery is avoided saving money, time and dangers of further infection and complications.

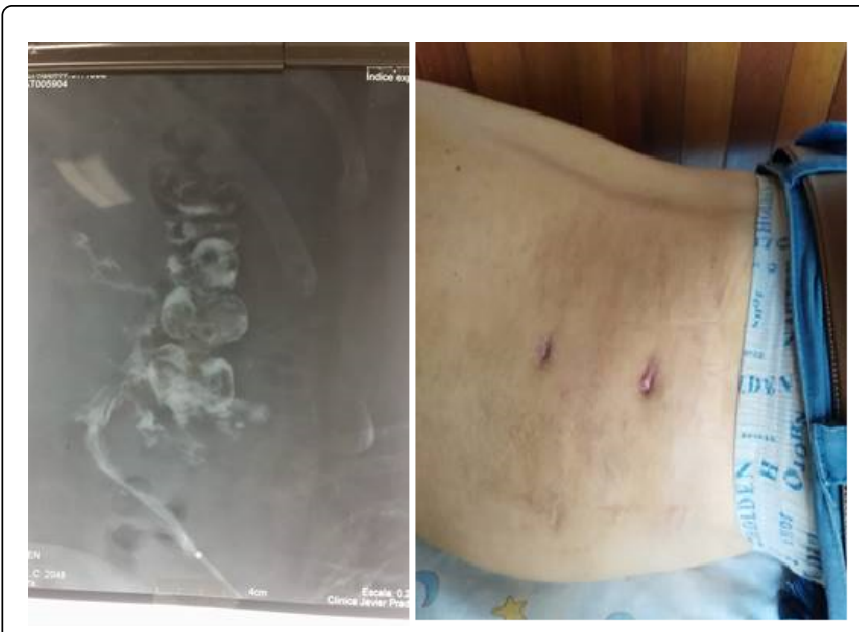

Figure 1: Non-invasive internal wound healing (cellsonic)
See the Figure 1, A patient was operated by laparoscopy for a left renal cyst. Eight months later inflammation was detected in the area of the operation. The approach was via left lumbar and a trocar was introduced. The cyst was extracted laparoscopically. It is possible that the colon was accidentally pricked and thus a fistula was formed colon to skin. The fistula was demonstrated by a fistulogram; introducing contrast by catheter proved the contrast indeed entered the colon. An abdominal surgeon was consulted and he indicated resecting the part of colon at the fistula.

Instead, Dr. Dario Rodriguez Escalante was invited to use his CellSonic medical machine, non-invasive and no drugs. The CellSonic treatment was 8 weekly sessions, which appears to have solved the problem and the photo shows the healed skin. It avoided major surgery which would have been necessary without CellSonic. 